\title{
REGIME E POLÍTICA DE INFORMAÇÃO ESTATÍSTICA
}

\author{
Nelson de Castro Senra
}

\begin{abstract}
Resumo: O texto analisa o controle ou administração da informação, com vista em dispor-se das informações necessárias ao controle ou administração das relações públicas (distantes). Isso exige uma política de informação, modo de agir sobre certo regime de informação. E sugere que a harmonização e sincronização da demanda e da oferta de estatísticas pressupõe a existência de uma instituição coordenadora, a ser definida no contexto da própria política.

Palavras-chaves: informação estatística; regime e política de informação.
\end{abstract}

\begin{abstract}
This text analyzes the need to control or administer information so that it can best serve the public and the public sector. Achieving this will require a clearly defined policy and governing regime. To ensure the harmonization and synchronization of supply and demand with regard to statistics, the author calls for the creation of a coordinating institution, the precise nature of which would be defined by information policy makers.

Key words: statistical information; information governing regime and information policy.
\end{abstract}

Information policy establishes the parameters within which information is controlled (created, synthesized, analysed, stored, disseminated, retrieved, and used) by human beings. There is interest in information policy because: 1) information control problems have not been solved, and 2) there is a belief that these problems should be solved. These problems are often exceedingly complex.

Robert H. Burger (1993:65)

$\mathrm{C}$ ontrolar a informação! Pois, há de se fazê-lo, não para segredá-la, mas antes para torná-la disponível ao controle diuturno das relações sociais e econômicas (comerciais e financeiras), em contextos privados e públicos (neste caso, pelas políticas públicas, nas quais as ações de mudanças são promovidas e/ou estimuladas). Administra-se a informação!

Entenda-se por controlar a informação ações do tipo influenciar, monitorar, fiscalizar, dirigir, regular. Ações que se darão sobre todas as etapas do complexo processo de elaboração, de estruturação, de utilização da informação, com vista em tornar ou manter seu ciclo vital e total devidamente harmonioso. ${ }^{1}$ Tudo isso, mediante política de informação.
Por essas ações, que têm por objeto praticar controles no campo das relações públicas, fica claro que a política de informação conformará, ela própria, um tipo ou uma forma de política pública, uma das mais recentes, entre as muitas criadas pelos governos (Burger, 1993). E essa inexperiência ou imaturidade será uma das dificuldades a serem abordadas e superadas.

Historicamente, mais e mais as transações econômicas (comerciais e financeiras) foram expandindo-se, alcançando terras e povos distantes, e mais se tornava essencial poder-se contar com controles, nunca fáceis de se dispor. Para controlar e dominar o distante, impunha-se conhecêlo para obter-se informações, que, devidamente trabalhadas, ofereciam dele um conhecimento superior ao conhecimento primitivo (ou nativo).

Atualmente, com as fronteiras territoriais e institucionais mais e mais se esmaecendo, intensificando, diversificando e espraiando as transações econômicas (comerciais e sobremodo financeiras), com distintos reflexos nas relações culturais, mais vital se torna haver controles, em formas e em conteúdos cada vez mais refinados e sofisticados. Com a abertura das fronteiras, claro, o distante fica 
mais distante; donde, mais e melhores informações são demandadas, sob pena de se perder o controle dos fatos ou dos eventos distantes que intervêm no aqui e no agora do presente. E esse será um dos grandes desafios a serem atacados pelos produtores de informação.

E por falar de informação, matéria-prima do controle do distante, convém lançar-lhe iluminação, seguindo o caminho de Bruno Latour. Assim, entendamos que: "A informação não é um signo, e sim uma relação estabelecida entre dois lugares, o primeiro, que se torna uma periferia, e o segundo, que se torna um centro, sob a condição de que entre os dois circule um veículo que denominamos muitas vezes forma, mas que, para insistir em seu aspecto material, eu chamo de inscrição" (Latour, 2000:22) (grifos no original). E, seguindo, tenhamos presente que: "A produção de informação permite, pois, resolver de modo prático, por operações de seleção, extração, redução, a contradição entre a presença num lugar e a ausência desse lugar. Impossível compreendê-la sem se interessar pelas instituições que permitem o estabelecimento dessas relações de dominação, e sem os veículos materiais que permitem o transporte e o carregamento" (Latour, 2000:24) (grifo nosso).

Depois, em uma alusão aos antigos viajantes em suas tradicionais expedições, afirma o autor em tela: "Verifica-se que a informação não é uma 'forma' no sentido platônico do termo, e sim uma relação muito prática e muito material entre dois lugares, o primeiro dos quais negocia o que deve retirar do segundo, a fim de mantêlo sob sua vista e agir à distância sobre ele. Em função do progresso das ciências, da freqüência das viagens, da fidelidade dos desenhistas, da amplitude das taxionomias, do tamanho das coleções, da riqueza dos colecionadores, da potência dos instrumentos, poder-se-á retirar mais ou menos matéria e carregar com mais ou menos informações veículos de maior ou menor confiabilidade" (Latour, 2000:23-4). Para controlar o distante, mais exatamente, suas ações, diretas e indiretas, há de se controlar suas informações.

Por fim, fazendo uma última citação, veja-se o autor em pauta tratando das aves levadas a algum centro: "Em comparação com a situação inicial, em que cada ave vivia livremente em seu ecossistema, que perda considerável, que diminuição! Mas, em comparação com a situação inicial, em que cada ave voava invisível na confusão de uma noite tropical ou de um amanhecer polar, que ganho fantástico, que aumento! O ornitólogo pode então, tranqüilamente, em local protegido, comparar os traços característicos de milhares de aves tornadas comparáveis pela imobilidade, pela pose, pelo empalhamento. O que vivia disperso em estados singulares do mundo se unifica, se universaliza, sob o olhar preciso do naturalista. Impossível, é claro, compreender este suplemento de precisão, de conhecimento, sem a instituição que abriga todas essas aves empalhadas, que as apresenta ao olhar dos visitantes, que as marca por um fino jogo de escrita e de etiquetas, que as classifica por um sistema retificável de prateleiras, de gavetas, de vitrines, que as preserva e as conserva borrifando-as com inseticidas" (Latour, 2000:25-6) (grifo nosso).

Mutatis mutandis, diga-se o mesmo da informação estatística.

De fato, as estatísticas configuram múltiplos organizados, expressando-os na linguagem dos números, que se quer, na tradição científica ocidental, objetiva e universal. Entretanto, em seu processo produtivo, agregam-se (superam-se) registros individuais (sobre pessoas e coisas); tomam-se e reúnem-se aspectos observáveis e registráveis das individualidades, e, ao fazê-los, passa-se a dizer do todo (do conjunto, do coletivo) e não mais das partes. Ora, tenha-se presente que essas partes, por serem diferentes, heterogêneas, não são agregáveis, em si mesmas, a menos que se lhes atribua ou lhes destaque algum elemento em comum, por meio de algum princípio de equivalência; dessa forma, serão observados e registrados os aspectos individuais que previamente configuraram os múltiplos organizados.

Desse modo, como tudo na ciência e na pesquisa (naturais e humanas), as estatísticas são mensurações construídas das realidades, e isso não lhes tira o caráter objetivo, em especial o de relevância e importância. Embora, em um primeiro instante, a realidade seja reduzida e diminuída, porquanto perdendo-se a exuberância das individualidades, em um segundo instante ela é amplificada, ou seja, se é fato que se perde a riqueza das unidades também é verdade que se ganha a riqueza do coletivo. E como se controla coletividades e não individualidades, ou, melhor dizendo, controla-se individualidades em meio a coletividades, a informação estatística, com sua dupla força semântica e sintática, assume papel de extrema relevância: objetivamente aproxima o distante; torna presente o distante.

Não por acaso, é entendida como tecnologia de distância, ou seja, como procedimento formalizado de controle ou de domínio, dessa forma, encaixando-se à maravilha 
como tecnologia de governo e de poder, com capacidade transformadora para intervir em eventos para mudá-los. Pessoas e coisas distantes são trazidas à presença dos decisores (às suas mesas) na forma de algumas tabelas e de alguns gráficos, quiçá, sempre que possível, na forma de mapas (cartogramas). Por exemplo, toda uma população, em sua complexidade, nos é revelada por inteiro (em aspectos seletivos) em poucas folhas de papel (o mundo real se faz em um mundo de papel), de modo que se permita que ações sejam promovidas e estimuladas, que decisões sejam tomadas. Pelas estatísticas, fazem-se discursos de verdade! $!^{2}$

Desde tempos imemoriais, as estatísticas vêem sendo um dos veículos de controle mais desejados para a formação dos Estados e para a condução dos governos; em um primeiro momento para o trato das finanças e da guerra, pouco a pouco, para o trato de um sem-número de domínios de governo, sociais e econômicos (Giddens, 2001). Até que no tempo presente, velozmente, emergem domínios de governo difíceis de se abordar, como, por exemplo, a chamada economia informal e mesmo a temida e perigosa economia ilegal, sem ignorar que a mensuração da economia formal continua essencial. Ao ampliar-se o campo do controle público (na forma de variadas políticas públicas), aumenta-se o âmbito da informação a ser controlada (administrada), nos termos vistos antes.

A demanda por estatísticas cresce e diversifica-se. Haverá estatísticas públicas e privadas (estas fruto de uma poderosa e florescente indústria privada). As estatísticas públicas, afetas às agências públicas de estatística supondo dispor-se do amparo das ciências e de adequados métodos de pesquisa -, terão de lutar por recursos escassos, distribuídos a diferentes atores nas esferas federal, estadual e municipal. Pois, definir as agendas das agências públicas de estatística resulta tarefa penosa, e mais ainda o de articulá-las, com vista em sincronizar e harmonizar os resultados desejados e desejáveis (Schwartzman, 1997). Pese a inegável dificuldade, impõe-se fazê-lo, razão de haver uma instituição coordenadora, formalizada e legalizada mediante uma política de informação estatística. ${ }^{3}$

\section{POLÍTICA DE INFORMAÇÃO ESTATÍSTICA: CONCEPÇÃO}

Não é simples e imediato conceber uma política de informação. A começar, pelo fato da informação ser seu cerne, seu centro, seu ponto focal. E, por mais que se avance na compreensão da informação, ela continua um claro enigma, que tem ambivalências e mesmo ambigüidades (Demo, 2000). Portanto, tratar de informação é enfrentar polêmicas (Burger, 1993).

Mesmo a informação estatística, em que pese o caráter objetivo e universal dos números que a expressam, provoca polêmicas. Não obstante, a ordem da sintática, a informação estatística é fortemente semântica; são construções amparadas nas ciências e na pesquisa, o que significa afirmar que são explicáveis e defensáveis, mas, de todo modo, não há de se desconhecer que os resultados seriam outros, se outros fossem os conceitos e os processos escolhidos e adotados (Besson, 1995). Isso significa que não se pauta apenas no plano da demonstração, locus do racional, mas também no plano da argumentação, locus do razoável; vale repetir, mesmo pautado nas ciências, o viver das pesquisas cotidianas é um eterno conviver com incertezas, indecisões e inseguranças. Argumenta-se, inclinando-se para uma adesão pela persuasão quando a tônica é posta nos resultados, bem assim, pendendo-se para uma adesão pelo convencimento quando a tônica é posta nas premissas (as razões para eventuais resultados).

Outras razões fazem difícil a concepção de uma política de informação. Tratar de política, dar-lhe sentido límpido, em que pesem os avanços da ciência política, é muito difícil, se não mesmo impossível, tanto quanto a questão da informação. Pois, ademais das dúvidas que seus termos-chaves, informação e política, provocam, na raiz de toda política de informação está a idéia de escolha, de difíceis escolhas sociais, não raro em meio a disputas acirradas. Como para fazer-se escolhas há de se dispor de informações, há de se pensar nas fontes de informações que alimentam a política de informação. Ora, a política de informação volta-se à geração de políticas públicas, na razão em que lhes organiza as necessárias informações, orientando-lhes as escolhas, logo, parece imediato dizer-se que será delas que lhe virá a informação necessária. Em suma, para cumprir seu destino de política pública, direcionada às diversas políticas públicas, orientando-as, uma política de informação precisa afinar-se com tais políticas públicas, de modo que oriente, a si própria, em suas escolhas e em suas disputas (Burger, 1993).

Posto isso, em que pese tantas dificuldades, define-se a política de informação como o "conjunto das ações e decisões orientadas a preservar e a reproduzir, ou, a mu- 
dar e substituir um regime de informação" (Gómez, 1999). Regime de informação é o conjunto (mais ou menos estável) de redes (relações) formais e informais nas quais as informações são produzidas, organizadas e transferidas de diferentes produtores, por meio de diversos meios, canais e veículos, a diferentes destinatários ou receptores de informação, generalistas ou especialistas (Frohmann, 1995); pois, assim, no âmbito dos regimes de informação, naturalmente intrincados e complexos, dão-se conflitos, com a manifestação de vontades plurais. ${ }^{4}$ Enfim, definida e negociada ou negociada e definida a política, resultado da vontade de sujeitos coletivos, há de se fazer sua gestão, para o quê, ainda que seja possível e desejável contar-se com uma racionalidade instrumental, não será suficiente, cabendo pautar-se nos valores e nas metas da própria política. ${ }^{5} \mathrm{E}$ mais, nada obsta que o gestor, como instituição, tenha seus contornos desenhados no contexto da própria política, mesmo que seja oportuno e vantajoso que se o faça.

Tudo isso, levando em conta os contextos culturais e políticos, em meio às várias tradições formadas e cristalizadas, a ditarem limites às ações ideais (a sugerir a tentação de um pensar mais indutivo que dedutivo, pese as políticas formais e legais serem, em sua essência, dedutivas). Como seja, a política alcançada, no limite do possível, deverá concretizar-se conforme textos legais, bem assim, por meio de diretrizes e regulamentos, mas sem os excessos de legalismo (que é a exagerada crença na onipresença das leis, com o risco de se cair no desprezo pela realidade) e sem os excessos de formalismo (que é o perigoso desconsiderar das condições de aplicação das leis, com o risco de se incorrer no paradoxo de haver leis que não se aplicam na prática). E, por melhor que seja a política, sempre haverá o risco de que, ao fim, ela não consiga promover um equilíbrio estável e durável, como seria desejável, donde, precisará ter flexibilidade e dinamismo para ajustar-se a situações cambiantes. Não obstante, enquanto vigindo, com dado conteúdo, em determinado formato, deverá ser seguida e cumprida rigorosamente.

\section{POLÍTICA DE INFORMAÇÃO ESTATÍSTICA: FORMULAÇÃO}

Então, transpondo à informação estatística, sua política deverá tratar, primeiro, da demanda ex ante que funda a oferta, segundo, da oferta em suas etapas de produção e de disseminação (esta, voltando-se à uma demanda $e x$ post), e terceiro, da criação de uma instituição competen- te para promover a sincronização e a harmonização da demanda e da oferta. Está-se falando da criação de uma instituição coordenadora dos sujeitos coletivos em suas ações e decisões cognitivas.

E segue a questão de como negociá-la, enunciando-a. Ora, a via mais simples e imediata, por sua inegável senioridade, seria fazê-lo pelo IBGE, há 65 anos a agência nacional de estatística. No entanto, ainda que seja razoável afirmar que saberia fazê-lo, não é certo e claro que o queira, ao menos não o manifesta publicamente. Como seja, quando se tem em mente que nada se faria de profundo e duradouro, na seara das estatísticas, sem sua presença e atuação, o IBGE deveria abraçar esta idéia claramente.

\section{Demanda Ex Ante das Estatísticas}

Chaves da Política de Informação - Em um primeiro momento, atores ou agentes postados nos vértices do triângulo da demanda - governo, mercado (empresas), comunidade (sociedade) - terão seus desejos e suas necessidades por estatísticas devidamente observados e registrados.

Não é fácil fazê-lo, em face da diversificação e da sofisticação com que se manifestam, não raro com fluidez e com pressa; quer-se mais e melhores informações, e se as quer para ontem, só o aqui e agora parece contar. Ora, como toda informação, estatística só estará disponível amanhã (ou mesmo depois de amanhã), se sua produção tiver sido iniciada ontem (ou mesmo anteontem), e se hoje tiver sido continuada. Isso não é fruto de vontade, mas de um ciclo técnico; está-se diante de um imperativo tecnológico, de difícil rompimento (relaxamento).

Enfim, passou-se o tempo em que a demanda das estatísticas tinha o ordenamento do planejamento nacional e que se podia atendê-la (oferta) sob o manto (quase único) da contabilidade nacional. Hoje, está claro, os domínios de governo perderam a uniforme simplicidade do planejamento nacional (não que fosse simples enunciálo e praticá-lo, longe disso), envolvendo-se num emaranhado de políticas públicas, não raro de caráter regional e local, não mais de caráter nacional, nem enfática nem necessariamente.

Então, entre as muitas estatísticas desejadas (devidamente observadas e registradas), em um segundo momento, será preciso apontar aquelas cuja produção caberá às agências públicas de estatística. Quais sejam, as que atendam ao critério do desejável, visto se referirem a temas/assuntos que já estejam compondo as agendas de governo, e que levem 
à formação das políticas públicas. Está-se falando de uma dimensão sistêmica, apropriada salvaguarda para as agências públicas de estatística, em face da inconstância do desejado, dinâmico acima de tudo. Contudo, não se veja o desejável como algo estático por excelência, mas apenas como algo que tem uma dinâmica muito mais lenta, mas, de todo modo, passando por mudanças.

Assim, para tratar do desejado e do desejável, em si mesmos, separadamente, e, sobremodo, em suas articulações, bem conviria poder-se contar com um Conselho Estratégico de Informação, como uma institucionalidade do espaço político inerente à demanda (claro, com representação democrática do triângulo da demanda). Ele seria, então, como que o guardião do pilar da pertinência (relevância e abrangência) e do pilar da utilidade (combinação e comparação), os quais, incorporados ao programa de trabalho, guiam a oferta (quando se estará promovendo a interdependência entre as dimensões sociopolitica e técnico-científica que configuram as informações estatísticas).

Chaves do Regime de Informação - Ao tempo da demanda, legitimamente, manifesta-se a dimensão sociopolítica das estatísticas, desejando-se informações comparáveis e combináveis, que cobram de modo abrangente os mais relevantes domínios públicos de governo. A esse tempo, dois pilares serão assentados:

- o da utilidade, com os aspectos da combinação e da comparação;

- o da pertinência, com os aspectos da relevância e da abrangência.

A demanda de estatísticas será vista como o desejo e/ ou a necessidade de atores ou agentes postos nos vértices do triângulo da demanda: governo, mercado (empresas), comunidade (sociedade). Para revelá-la, será preciso:

- observar a demanda do tempo passado em documentos diversos tornados públicos, pelo setor público ou pelo setor privado; trata-se de uma análise estática, sabidamente $a$ posteriori dos acontecimentos;

- observar a demanda do tempo presente quando da definição dos programas públicos e privados; trata-se de análise dinâmica, que procura conquistar presença ao tempo da definição das políticas públicas;

- observar a demanda do tempo futuro em congressos, seminários, conferências, colóquios, jornadas, voltados a exprimir as tendências das informações; trata-se de uma análise de abordagem futurística.
A demanda de estatísticas referidas aos tempos passado, presente e futuro, deverá revelar os desejos e/ou as necessidades dos setores governo, mercado (empresas) e comunidade (sociedade); contudo, tratando-se de informações a serem tornadas públicas, deverá ser observada e registrada com base no setor governo, até por ser historicamente seu demandante mais constante e por ser seu ofertante mais robusto. Será preciso:

- fazer emergir um plano de demanda (desejada), em proposta executiva, mediante atuação de atores ou agentes do setor governo, olhando-se todos os vértices do triângulo da demanda (o próprio governo, bem assim, o mercado e a comunidade);

- submeter o plano de demanda (desejada) à avaliação e à validação de um Conselho Estratégico de Informações, a ser formado por legítimos e autênticos representantes de todos os vértices do triângulo da demanda (governo, mercado, comunidade).

A demanda (desejada) de estatísticas apresenta natural fluência e fluidez, fazendo-se e desfazendo-se com incrível rapidez, donde sua detecção e sua avaliação deverão ser atividades contínuas, decidindo-se com critério e com isenção os instantes adequados de resposta (demanda desejável). Será preciso:

- tornar contínuo o esquema de observação da demanda (desejada) manifesta nos tempos presente e futuro, registrando-a sistematicamente;

- submeter ao Conselho Estratégico de Informações as novidades, dando-lhe saberes técnico-científicos para a tomada de decisões (demanda desejável).

O Conselho Estratégico de Informações, devidamente institucionalizado, e representativo dos demandantes (governo, mercado, comunidade), a fim de poder legitimar a demanda de estatísticas (já no plano do desejável), e promover argumentadas deliberações, precisará de uma animação executiva. Será preciso:

- oferecer sugestões para sua agenda de trabalho, subsidiando os debates com estudos e reflexões, sintéticas e analíticas;

- secretariar seu cotidiano, levando-o a funcionar regular e fluentemente, ademais, participando vivamente dos debates.

\section{Oferta (Produção e Disseminação) das Estatísticas}

Chaves da Política de Informação - Então, havendo um programa de trabalho, depois do embate entre o desejado 
e o desejável, a orientar a produção (primeira etapa da oferta), tenha-se por hipótese que não faltarão recursos (humanos, materiais - técnicos e tecnológicos -, financeiros) à sua realização, nas várias agências públicas de estatísticas: federais, de caráter temático, estaduais e municipais, todas em uníssona afinação com a agência nacional de estatística.

Num primeiro momento, em tempo de concepção, será feito um diálogo com a ciência (locus da verdade); nesse instante, a questão será saber se as ciências já pensaram naqueles domínios de governo, objetos da demanda, e, se ao pensá-los, já lhes deram contornos definidos; dito de outra forma, a questão central é saber se há conceitos sólidos o bastante para guiar as decisões fundadoras das pesquisas por parte dos pesquisadores (aquilo que estiver bem conceituado terá contornos mais visíveis e, em conseqüência, serão observados com mais propriedade, mais competência, sobremodo, com menos polêmica). Definese, então, o marco teórico-conceitual que ancorará a elaboração das estatísticas.

Em um segundo momento, será feito um diálogo com a pesquisa, com todas as incertezas, as inseguranças e as indecisões que lhes são inerentes (tendo-se presente que o embate entre as teorias e as práticas depende sempre de sistemas de interpretação). Aqui, a questão será saber se já se dispõe de um marco teórico-processual consistente e suficiente e sólido, muito além dos marcos típicos do ensino acadêmico. Esses, por mais que ajudem, e ajudam muito, não bastam à condução do trabalho de campo, quando serão obtidos (por delegação da observação) os registros de natureza individual (estatísticos ou administrativos), nem na condução do trabalho de apuração, crítica e análise, quando aqueles registros individuais serão transformados nas estatísticas propriamente ditas.

Em suma, já foi dito, as estatísticas são mensurações construídas das realidades, que têm por base, não individualidades singulares, mas antes, individualidades relacionadas, devidamente articuladas por algum princípio de equivalência, e isso não lhes tira a objetividade, expressa nos números (e que lhes empresta tanta relevância e importância). Mesmo que esta objetividade seja objetivada, vale dizer, seja uma objetivação, nada desabona os resultados, desde que as escolhas e as decisões sejam postas, no tempo certo e justo, ao crivo da contradição. Contudo, não se perca de vista de que essa objetivação, a forte marca semântica das estatísticas, estreita os limites de novos significados atribuíveis às estatísticas. ${ }^{6}$
Como seja, as estatísticas produzidas, ao fim e ao cabo, devem ser feitas de modo permanente e sistemático (pilar da continuidade), assentando-se em conceitos e processos adequados (pilar da validade), seja no uso dos registros estatísticos, seja no uso dos registros administrativos. Terminada a produção, ter-se-á uma base de dados, devidamente estruturada, com vista na realização da disseminação, que deve ter em mente liberar os usuários, o mais possível, da mediação dos especialistas, de modo a darlhes amplo acesso às estatísticas (na máxima abertura possível, atendido o sigilo), facilitando-lhes sua apreensão e sua aceitação (pilar da visibilidade).

De fato, uma vez que cada usuário perfaz um universo distinto, com desejos e com necessidades particulares e específicas, o sucesso da disseminação implicará mesmo o intenso promover e estimular do auto-atendimento, o que não impede de haver sempre espaço para um atendimento padronizado (na forma de produtos e serviços ajustados a uma tipologia básica de usuários) e para um atendimento personalizado (na forma de produtos e serviços ajustados aos desejos de alguns usuários, sob a assessoria de especialistas nas estatísticas, conhecedores de suas metodologias). Há de haver um equilíbrio entre essas três formas de atendimento, norteadas, todas elas, por uma demanda ex post.

Por fim, par a par com a criação de um Conselho Estratégico de Informações com vista em dar-se formalidade institucional à manifestação da dimensão sociopolítica das estatísticas, ao tempo da demanda, conviria criar-se, ao tempo da oferta, um Conselho de Especialistas em Informações, a fim de dar-se formalidade institucional à manifestação da dimensão técnico-científica das estatísticas. Dois conselhos independentes, por certo, mas que precisariam trabalhar afinados, o que se daria pela instituição coordenadora.

Chaves do Regime de Informação - Ao tempo da oferta, produção e disseminação, manifesta-se a dimensão técnico-cientifica das estatísticas, quando as informações tornadas acessíveis de forma sistemática e permanente deverão ser aceitáveis a fim de estarem refletindo de modo adequado e preciso os domínios públicos definidos ao tempo da demanda. Três pilares serão assentados:

- o da validade, com os aspectos da adequação e da precisão;

- o da visibilidade, com os aspectos da acessibilidade e da aceitabilidade; 
- o da continuidade, com os aspectos da sistematização e da permanência.

No pilar da validade, quanto à adequação, há que se assentar um marco teórico-conceitual e, quanto à precisão, o teórico-processual, dessa forma, promovendo-se a consolidação da passagem do desejado/desejável expresso na demanda ao possível expresso na oferta. ${ }^{7}$ Será preciso:

- no marco teórico-conceitual, conformar os princípios de equivalência (quando as identidades entre diferentes serão estabelecidas) e os princípios de padronização (de natureza conceitual, espacial e temporal). À falta de saberes conhecidos e reconhecidos, será preciso promoverse estudos com vista em seu surgimento;

- no marco teórico-processual, conformar um processo de pesquisa, no que tange às etapas de organização, observação e exploração, com vista na perfeita aplicação do previsto no marco teórico-conceitual. À falta de saberes conhecidos e reconhecidos, será preciso promover-se estudos com vista em seu surgimento;

- no sentido de ambos os marcos teóricos será conveniente promover-se laboratórios de metodologias estatísticas, de processamento informático (apuração, crítica e análise, organização e armazenagem), de observação delegada (trabalho de campo). Trata-se de fazer pesquisa (no singular) de modo que se possa fazer pesquisas (no plural);

- no sentido de ambos os marcos teóricos, ainda, tornar público os métodos de pesquisa, os princípios de equivalência e de padronização, na forma de classificações, de ordenamentos, de inventários de fontes, de glossários de termos, entre outros. E, em especial, tornar pública a questão do sigilo.

Equilibrar a utilização dos registros individuais, de natureza administrativa e de natureza estatística, fundadores das informações estatísticas, enquanto expressões coletivas (com o rigoroso respeito ao sigilo). Será preciso fazer que:

- os registros administrativos sejam mais amplamente utilizados na geração das informações estatísticas, não só na esfera municipal em que é dominante, mas também nas esferas estadual e federal (de caráter temático), de modo que reduza custos e prazos e melhor atenda à demanda;

- os registros estatísticos sejam menos criados e mais abertos de modo que sejam mais bem usados, ou seja, é de se esperar que as pesquisas geradoras dos registros estatísticos resultem mais e mais de programas integrados, e que evitem atuações avulsas, demasiado temáticas; - os registros individuais (administrativos e estatísticos) tenham definidos leis e normas, regulamentos e procedimentos, com intuito de se dar aos informantes absoluta garantia de sigilo sobre as informações prestadas, bem assim, atentar para o pleno direito dos informantes à privacidade.

Uma base de dados estruturada será o ponto de chegada da produção e o ponto de partida da disseminação, logo, será preciso que a disseminação seja pensada ao tempo mesmo da produção, como condição ao fixar do pilar da visibilidade, tornando as informações acessíveis e aceitáveis. A disseminação, lembre-se, volta-se a uma demanda ex post. Será preciso:

- promover uma cultura de atenção aos usuários, com vista em aumentar-lhes a satisfação, liberando-os da mediação de especialistas. Nesse sentido, há de se mudar as relações temporais e espaciais dos usuários com as informações, e que se eleja o auto-atendimento como modo ideal;

- entretanto, como o auto-atendimento dificilmente assumirá proporção universal, cuidar das formas clássicas de atendimento: atendimento padronizado, na forma de produtos e serviços ajustados a uma tipologia de usuários, e atendimento personalizado, na forma de produtos e serviços ajustados aos desejos de usuários preferenciais;

- quanto à realização das três formas de atendimento, desenvolver uma infra-estrutura (na forma de tecnologias) e uma info-estrutura (na forma de metainformações) de informações. Em especial, tornar o geoprocessamento o mais possível disponível e utilizável no atendimento;

- com vista na dinamização do atendimento, em suas três formas, oferecer estudos e análises interpretativos e explicativos das realidades complexas: se anônimos, que se tenha o cuidado de preservar a neutralidade institucional; se assinados, que se tenha o cuidado de liberar a instituição das opiniões veiculadas em caráter pessoal.

Como um elo entre os pilares da validade e da visibilidade, promover o pilar da continuidade, ou seja, esperase que as informações tornadas disponíveis o sejam de modo sistemático e permanente antes que de modo avulso e eventual, para tanto, agindo em nível executivo e em nível legislativo. Será preciso:

- empenhar para que os recursos necessários (humanos, materiais, financeiros) estejam sempre disponíveis, sob 
pena da perda das aplicações anteriores. (Tenha-se presente que as produções iniciadas ontem, se interrompidas hoje, não estarão disponíveis amanhã, ou, as produções só estarão disponíveis depois de amanhã se iniciadas hoje.);

- estruturar um Conselho de Especialistas em Informação que possa atuar como aliado na defesa da continuidade, e que ateste a qualidade das opções feitas nas fases de produção e de disseminação. É essencial que as informações tornadas disponíveis sejam estáveis, explicáveis, defensáveis, incontroversas, enfim, comparáveis e combináveis.

Por fim, promover um intercâmbio de conhecimento especializado, que mantenha em evidência a importância e as especificidades das informações estatísticas, e que mostre suas possibilidades e suas limitações, tanto com os integrantes dos conselhos Estratégico de Informações e de Especialistas em Informações, quanto com o público em geral. Será preciso:

- tornar públicas as tendências da informação, da informação estatística, da sociedade da informação, revelando o caminhar das principais instituições produtoras, internos e externos, mediante divulgação de textos seletos: em versão integral, quando de conteúdo geral e amplo; em versão condensada, quando de conteúdo específico;

- envidar esforços para que esses textos sejam debatidos e apreendidos, para tanto desenvolvendo mecanismos de esclarecimento, promovendo a participação de pessoas capazes, dispostas e disponíveis: em espaço real, participando de ambientes formais; em espaço virtual, dialogando a distância com os interessados.

\section{Coordenação da Demanda e da Oferta das Estatísticas}

Chaves da Política de Informação - A relação, de um lado, entre a demanda ex ante e a oferta (produção), e, de outro lado, entre a oferta (disseminação) e a demanda ex post, não se faz e não se fará no livre jogo das forças de mercado, mas, antes, com alguma instituição, coordenadora, capaz de promover políticas e sistemas, e de buscar e construir harmonias.

Assim, coordenar configura uma atividade não $a$ posteriori da demanda e da oferta, mas antes uma atividade que as promovam e que as harmonizem, no interior e no limite de um mandato acordado entre pares, quais sejam, as agências públicas de estatística: federais, de caráter temático, estaduais e municipais, em comum acordo com a agência nacional. Dever-se-á atuar no seio de uma rede ou cadeia de alianças, sintonizando as comunicações, com vista em assentar-se o pilar da integridade (credibilidade e legitimidade).

Por demais, entenda-se por coordenar a faculdade, a capacidade, a disposição de se organizar e de organizar entidades associadas. Trata-se de conjugar, de concatenar, de interligar, enfim, de sincronizar e de harmonizar elementos e atividades, vale dizer, atores, em seus saberes e em seus pensares. Coordenar não será apenas um ato de vontade, mesmo que de boa vontade, mas antes um ato de poder, com a um saber fazer. Ambos, o poder fazer e o saber fazer estarão apostos na política de informação; em um exercício laborioso de negociação.

A instituição coordenadora deverá empenhar-se para que no interior da rede ou cadeia de alianças os diversos especialistas envolvidos possam contar com a melhor das tecnologias de informação (processamento) e de comunicação, de modo que, além da aquisição de saberes existentes, pratiquem laboratórios capazes de propiciar avanços conceituais e processuais na geração das estatísticas (sempre com vista no aumento da qualidade dos resultados, bem assim, à redução dos prazos). A instituição coordenadora praticará uma intensa e variada accountability em todas as etapas de trabalho; documentos diversos devem ser elaborados e divulgados amplamente, em conteúdos analíticos e explicativos, em formatos detalhados e resumidos, em veículos impresso e eletrônico.

A instituição coordenadora poderia integrar a estrutura do IBGE, em seu papel de agência nacional de estatística, no alto de seus 65 anos de existência, seja por dispor, seja por avançar, como poucos, do saber fazer técnico necessário à coordenação (e está-se tratando dos instrumentos de coordenação, na forma de classificações, de padronizações, entre outros). No entanto, por abraçar a técnica, que isola ao máximo a política, acaba por não ter o saber fazer político também necessário à coordenação. Poder-se-ia idealizar uma instituição coordenadora independente, fora do IBGE, o que, pese a tentação, não será de fácil realização, tendo-se que envolvê-lo. Então, a solução talvez esteja, uma vez mais, na média, em algum ponto entre ter a instituição coordenadora dentro ou tê-la fora do IBGE, e isso precisaria ser negociado. ${ }^{8}$

Chaves do Regime de Informação - A instituição coordenadora poderá ter um contorno autônomo ou associado, a depender da história e da cultura do país, mas que seja um saber próprio, especializado. 
A instituição coordenadora exercerá uma atividade reguladora, visando, no limite, ao equilíbrio das dimensões sociopolítica (ao tempo da demanda) e técnico-científica (ao tempo da oferta) das estatísticas. Deverá exercer sua atividade reguladora ${ }^{9}$ na extensão do mandato que se lhe atribua, ditando-lhe os contornos, e que podem ser de caráter:

- Executivo, atuando nos tempos da demanda e da oferta, podendo receber o direito de concessão e de fiscalização da produção e da disseminação (tempo da oferta) das estatísticas.

- Legislativo, validando em conselhos a moldura legal e formal (diretrizes, regulamentos, interpretações, enfim, medidas e resoluções), necessárias ao desenrolar de sua função executiva.

- Judiciário, avaliando e julgando o cumprimento dos acordos, dos pactos, enfim, dos contratos e obrigações assumidos pelas partes, impondo-lhes as penalidades previamente estabelecidas.

A instituição coordenadora, independente da extensão do mandado que receba, deverá exercer seu poder de modo democrático, na prática de uma diuturna argumentação, resguardando as liberdades e as identidades de cada associado.

No interior e no limite do mandato recebido, a instituição coordenadora será o centro em torno do qual deverá orbitar a definição da demanda e a execução da produção e da disseminação (pelos vários atores ou agentes envolvidos), de modo que garanta aos diferentes resultados das diferentes pesquisas a força de serem comparáveis e combináveis.

O centro nacional, pela singular experiência acumulada, é o mais focal ao passar aos espaços local e global. O centro nacional não significa a negação da existência de centros nas esferas estaduais e municipais, conforme as necessidades. $O$ centro nacional não significa a afirmação de hierarquia, é apenas o mais focal a todas as esferas espaciais (federal, estaduais, municipais).

A instituição coordenadora promoverá relações funcionais no seio de uma rede ou cadeia de alianças, que busca um equilíbrio entre a liberdade inerente às redes e o aprisionar inerente às cadeias, enquanto promovendo sucessivas traduções nas linguagens dos participantes. Deverá promover, entre seus participantes, a identidade possível, no respeito às diferenças inevitáveis, que tem em mente um objetivo comum.
A instituição coordenadora, que melhor animar a rede ou cadeia de alianças, agirá com a finalidade da promoção de uma unidade ou identidade entre profissionais envolvidos com a elaboração das estatísticas; trata-se de figurar a atuação do estaticista, enquanto um profissional que mescla seu saber específico com um saber comum (de estatística e de informação). Para tanto, deverá conceber e estruturar um plano de formação funcional continuada, dos novos e dos antigos profissionais.

A instituição coordenadora deverá evidenciar seu caráter democrático exercendo uma intensa e variada accountability em todas as etapas do processo de trabalho, que garanta a instalação do mais abrangente de todos os pilares que fundam a elaboração das estatísticas: o pilar da integridade, com os aspectos da credibilidade (de dentro para fora, no trato sério da oferta) e da legitimidade (de fora para dentro, no trato sério da demanda). ${ }^{10}$

\section{POLÍTICA DE INFORMAÇÃO ESTATÍSTICA: APLICAÇÃO}

A política de informação, já foi dito, deve ser seguida e cumprida rigorosamente, enquanto estiver em vigor, e, supostamente, estando atualizada, afinada e ajustada às necessidades. Em definitivo, estando em vigor, não pode ser letra morta; mas não deve ser estática, não pode ser vista como imutável. Antes pelo contrário, deve trazer em si mesma a possibilidade da mudança, vale dizer, deve ser previdente, mas também maleável e pragmática. E fazê-la atuante deverá ser atribuição da instituição coordenadora, parte, ela própria, da política de informação.

Assim, será vital dar publicidade à política de informação, fazendo-a conhecida, tanto a ser cumprida, como a ser criticada, sempre que suas bases sociais e culturais tiverem sofrido mudanças. Deverá ser tornada pública pelos documentos específicos, com formato e conteúdo ajustados aos diferentes públicos. Há de se usar a Internet, naturalmente, bem assim, os recursos da Intranet e da Extranet (redes interativas).

A instituição coordenadora, garante a política de informação, deverá revelar o trabalho realizado, seu sucesso e seu fracasso, abrindo-se o processo ao controle social, por meio de relatórios analíticos e explicativos, detalhados e resumidos, impressos e eletrônicos. Deverá oferecer mecanismos de esclarecimento e de acompanhamento, bem como, mecanismos de captação e de avaliação das críticas e das sugestões de mudança. 


\section{CONSIDERAÇÕES FINAIS}

A concepção e a formulação da política de informação estatística passa por apreender e assimilar as chaves antes vistas. Elas procuram relacionar os elementos essenciais do processo de elaboração das estatísticas (regimes de informação), para os quais se haverá de assumir decisões (política de informação). A questão é saber como as agências públicas de estatística - federais, de caráter temático, estaduais e municipais, bem assim, a agência nacional estarão dispostas a entenderem e a praticarem suas atividades, fazendo-o de modo sincronizado e harmonizado; trata-se de decidir o contorno que se dará à política de informação, em face do grande regime de informação inerente à geração das estatísticas. E mais, trata-se, sobremodo, de se configurar a instituição coordenadora, enquanto a gestora da política de informação, fazendo-o no contexto da própria política; para além de revelar-se sua dimensão técnico-científica (instrumental, naturalmente racionalista) haverá que relevar-se sua dimensão sociopolítica (por certo argumentativa).

\section{NOTAS}

Versão bastante modificada do texto apresentado na mesa redonda "Estado, Sociedade e Políticas Públicas" no seminário "Conhecimento e Informação nas Sociedades da Comunicação", no Fórum de Ciência e Cultura da Universidade Federal do Rio de Janeiro, em 09 de junho de 2000. O autor reconhece dívida para com Luiz Henrique Proença Soares, da Fundação Seade, pelas valiosas reflexões recebidas em muitos e sempre prazerosos diálogos; mas não lhe cabe responsabilidade pelas idéias aqui desenvolvidas (o autor se sabe cabeça-dura). As opiniões aqui expressas são pessoais, podendo não coincidir com as opiniões vigentes nas instituições com as quais o autor mantém vínculo.

1. Ainda que em termos gerais, aí está, como logo se verá, as grandes linhas de um regime de informação.

2. Na expressão de Lord Kelvin: Quando você não consegue medilo... seu conhecimento é do tipo escasso e insatisfatório. Ao que se poderia acrescentar a expressão de Frank Knight, Prêmio Nobel de Economia: Bem, se você não puder medir, meça assim mesmo.

3. Não parece possível, nem adequado, nem necessário, haver uma única política de informação, mas apropriado a existência de políticas de informação temáticas e/ou setoriais.

4. O regime de informação no que tange às estatísticas está expresso nas subseções Demanda e Oferta - produção e disseminação.

5. Ver gestão da política de informação estatística nas subseções Coordenação e Instituição coordenadora.

6. Tomar-se as estatísticas apenas por sua força sintática, ignorando suas fronteiras semânticas, leva fácil à nefasta prática, por parte dos usuários, de "torturar os números", levando-os a dizer o que se queira.

7. No contexto desses marcos teóricos estará, por exemplo, as questões da amostragem, das bases cartográficas, das análises espaciais, dentre outros aspectos.
8. Tome-se os exemplos do Eurostat, no âmbito da União Européia, bem assim, os grupos e os comitês de trabalho, no âmbito do Mercosul.

9. Veja-se, em especial, Nunes (1998a).

10. Para uma discussão sobre os pilares da demanda, da oferta e da coordenação, tratados ao longo deste texto, veja-se Senra (2000).

\section{REFERÊNCIAS BIBLIOGRÁFICAS}

BARRETO, A. de A. "Perspectivas da Ciência da Informação". Revista de Biblioteconomia. Brasília, v.21, n.2, jul.-dez. 1997, p.15566.

. "Mudança estrutural no fluxo do conhecimento: a comunicação eletrônica". Ciência da Informação. Brasília, v.27, n.2, 1998. Disponível em: <www.ibict.br/cionline>.

BESSON, J.L. "As estatísticas verdadeiras ou falsas?” In: A ilusão das estatísticas. São Paulo, Unesp, 1995.

BURGER, R.H. Information policy: a framework for evaluation and policy research. Norwook, New Jersey, Ablex Pub. Corporation, 1993.

DEMO, P. "Ambivalências da sociedade da informação". Ciência da Informação. Brasília, v.29, n.2, maio-ago. 2000, p.37-42. Disponível em: <www.ibict.br/cionline>.

DOWBOR, L. O mosaico partido. Petrópolis, Vozes, 2000. [Em especial a Parte II: $O$ mosaico futuro. p.71-120]

FROHMANN, B. "Taking information policy beyond information science: applying the actor network theory". $23^{\text {rd }}$ Annual Conference: Canadian Association for Information Science, 1995. Disponível em: <frohmann@julian.uwo.ca>.

GIDDENS, A. Mundo em descontrole, o que a globalização está fazendo de nós. Rio de Janeiro, Record, 2000.

. O Estado-Nação e a violência. São Paulo, Edusp, 2001. [Em especial o cap.7: Poder administrativo, pacificação interna. p.193-216.]

GÓMEZ, N.G. de. "Da política de informação ao papel da informação na política contemporânea". Revista Internacional de Estudos Políticos. Rio de Janeiro, ano 1, n.1, abr. 1999, p.67-93.

LATOUR, B. Redes que a razão desconhece: laboratórios, bibliotecas, coleções. In: BARATIN, M. e JACOB, C. (orgs.). O poder das bibliotecas: a memória dos livros no Ocidente. Rio de Janeiro, UFRJ, 2000.

. A esperança de Pandora. Bauru: Edusc, 2001. [Em especial o cap.2: Referência circulante. Amostragem do solo da floresta amazônica. p.39-96.]

NUNES, E. "Reforma administrativa, reforma regulatória: a nova face da relação Estado-Economia no Brasil". Anais... XXII Encontro Anual da Anpocs, 1998a.

. "Mercado entre o alter e o ego do Estado". Insight/Inteligência. Rio de Janeiro, n.4, ago.-out. 1998b.

ROWLANDS, I. "Understanding information policy: concepts, frameworks and research tools". Journal of Information Science. v.22, n.1, 1996. p.13-25.

SCHWARTZMAN, S. "Legitimidade, controvérsias e traduções em estatísticas públicas". Teoria \& Sociedade. Belo Horizonte, n.1, 1997, p.9-38. Disponível em: <www.airbrasil.org.br/simon>.

"O futuro das estatísticas internacionais - uma visão do sul 1998". 3p. Disponível em: <www.airbrasil.org.br/simon>. 
SENRA, N. de C. "A coordenação, a argumentação e a comunicação das estatísticas, vértices de um mesmo triângulo". São Paulo em Perspectiva. São Paulo, v.12, n.4, out.-dez. 1998, p.92-8.

"Informação estatística: política, regulação, coordenação". Ciência da Informação. Brasília, v.28, n.2, maio-ago. 1999. Disponível em: <www.ibict.br/cionline>.

"Informação estatística: demanda e oferta, uma questão de ordem". DataGramaZero. v.1, n.3, jun. 2000. Disponível em: $<$ www.dgzero.org ou www.dgz.org.br>.
SEVECENKO, N. A corrida para o século XXI. No loop da montanha-russa. São Paulo, Companhia das Letras, 2001.

Nelson de Castro Senra: Economista, Professor na ENCE/IBGE

- Mestrado, Pesquisador no IBGE (ncsenra@alternex.com.br e senra@ibge.gov.br). 